\title{
Should the use of transcatheter aortic valve implantation be rationed?
}

Robert M. Sade, MD

See related articles by John E. Mayer on pp 771-3 and Grayson H. Wheatley on pp 774-5.

Transcatheter aortic valve implantation (TAVI) has great promise of helping patients with severe aortic valve disease who are not candidates for open surgery. It is an expensive technology, however, and some believe it should not be offered to every patient who is medically suitable to receive it - in other words, its use should be rationed.

The Ethics Forum, which comprises the membership of the American Association for Thoracic Surgery Ethics Committee and the Society of Thoracic Surgeons Standards and Ethics Committee, sponsored a debate on rationing TAVI at the 2011 Annual Meeting of the American Association for Thoracic Surgery. John E. Mayer, Jr, MD, argued the proponent position, ${ }^{1}$ Grayson H. Wheatley, MD, the contrariant ${ }^{2}$ regarding a hypothetical case, constructed to focus on the question of whether the offer of TAVI should be withheld from an elderly patient.

\section{THE CASE OF THE OLD MAN AND HIS VALVE}

The patient is 75 years old, and 10 years ago he received a 4-vessel coronary artery bypass graft, including the left internal thoracic artery to the left anterior descending coronary artery. He did well thereafter but has lived alone since his wife died 2 years ago; he has no children and no close relatives. Significant heart failure symptoms recently developed in the patient. Echocardiographic assessment now shows evidence of severe aortic stenosis with a calculated valve area of $0.8 \mathrm{~cm}^{2}$ and a mean gradient across the valve of $60 \mathrm{~mm} \mathrm{Hg}$. There is left ventricular hypertrophy, and the left ventricular ejection fraction is $40 \%$. Coronary

\footnotetext{
From the Division of Cardiothoracic Surgery, Department of Surgery, Institute of Human Values in Health Care, Medical University of South Carolina, Charleston, SC. This publication was supported by the South Carolina Clinical and Translational Research Institute, Medical University of South Carolina's Clinical and Translational Science Award Number UL1RR029882. The contents are solely the responsibility of the author and do not necessarily represent the official views of the National Center For Research Resources or the National Institutes of Health.

Disclosures: Authors have nothing to disclose with regard to commercial support.

Read at the 91st Annual Meeting of The American Association for Thoracic Surgery, Philadelphia, Pa, May 7-11, 2011.

Received for publication Feb 3, 2012; accepted for publication Feb 5, 2012.

Address for reprints: Robert M. Sade, MD, Department of Surgery, Medical University of South Carolina, 25 Courtenay Drive, Suite 7028, MSC 295, Charleston, SC 29425 (E-mail: sader@musc.edu).

J Thorac Cardiovasc Surg 2012;143:769-70

$0022-5223 / \$ 36.00$

Copyright (C) 2012 by The American Association for Thoracic Surgery doi:10.1016/j.jtcvs.2012.02.003
}

catheterization shows severe native coronary disease with all grafts patent and no new native coronary obstructions. Computed tomography scan reveals evidence of moderate to severe calcification of the ascending aorta, and the left internal thoracic artery passes directly under the sternum, and thus is at high risk of being damaged during reoperative sternotomy. In addition, the patient has moderate to severe chronic obstructive pulmonary disease (forced expiratory volume in 1 second $45 \%$ of normal) and a baseline creatinine of $1.8 \mathrm{mg} / \mathrm{d}$.

The patient is referred to Dr Sloan, an established cardiothoracic surgeon who participated in the initial Sapien (Edwards Lifesciences, Irvine, Calif) TAVI trial and has significant expertise with the procedure. Although Dr Sloan has determined that the patient is a medically acceptable candidate for TAVI, but not for aortic valve replacement, he wonders whether some advanced technologies such as this one are expanding the scope of health care beyond sustainable limits. He knows that the only reason to deny TAVI to this particular patient is consideration of nonmedical issues, that is, the patient's advanced age and lack of a social support system, and the expense of the procedure, and is undecided whether he should offer the procedure or, for the greater good, deny him its benefits.

\section{COMMENT ON THE DEBATE}

In the accompanying point-counterpoint discussion, Drs Mayer $^{1}$ and Wheatley ${ }^{2}$ wrestle with this question. Both writers consider neither age nor social status to be a critical determinant in deciding whether or not the procedure should be offered. Wheatley considers the question on the basis of financial analysis and 3 ethical principles: need, maximizing, and egalitarian. He concludes that the patient should be offered TAVI under the first 2 but perhaps not the last (the egalitarian principle of justice). Looking to the future, he is concerned about increasing pressures on physicians to carry out just such rationing.

Mayer ${ }^{1}$ takes a broader approach, looking at the issue from a systemic viewpoint. He distinguishes between the role of physicians as caregivers and as members of the medical profession, stating that the profession as a whole has a responsibility to control and monitor (which he considers to be different from rationing) the use of expensive technologies. Although he speaks of "controlled dissemination of this technology," Mayer also believes the information generated by this process will be sufficient for physicians and patients to make decisions that respect the interests of both patients and society. He does not directly answer the question of whether the physician in the vignette would 
be justified in not offering TAVI to a medically eligible patient because of high cost to society.

Bedside rationing is a relatively new role for physicians, yet the foundation of the healing relationship is the patient's trust that physicians will be primarily concerned for the patient's interests rather than their own or society's interests. Nearly every current code of ethics, including those of the American Association for Thoracic Surgery, ${ }^{3}$ the Society of Thoracic Surgeons, ${ }^{4}$ and the American Medical Association, ${ }^{5}$ places the interests of the patient as physicians' paramount responsibility. Bedside rationing - withholding the offer of a particular therapy from one's own patient despite a positive benefit-harm balance-is prima facie inconsistent with this responsibility. Both discussants recognize the primary obligation of physicians to patients. Wheatley ${ }^{2}$ believes bedside rationing of expensive new technologies will likely have to be rationed in the future.

Mayer, ${ }^{1}$ however, believes rationing can be avoided if rigorous data provided by the profession's monitoring of TAVI are used by physicians and patients for rational consideration, enabling the physician and patient together to limit TAVI to those who will benefit most. In the case presented, TAVI was medically indicated, but Dr Sloan wondered about how to weigh age, social situation, and cost in deciding whether to offer the procedure to the patient. Both discussants agree that age and social status are not determinants of suitability for TAVI, so cost remains as the central nonmedical issue. Mayer couples "control" of TAVI with monitoring, but it is unclear what it means to control a technology when "it will be critical that the patients be provided this information so that each may make their own decisions." In the presence of a positive benefit-harm balance, it is difficult to imagine patients refusing an offer of a life-prolonging, quality of life-improving procedure on the basis of avoiding an expense that will not be borne by either them or their survivors.

Critical to this discussion is current law and future policy development. The legislative battles over revisions of the Patient Protection and Affordable Care Act that are currently under way in Washington will eventually produce a health care system that will ultimately determine the shape and nature of the patient-physician relationship. Some reforms will empower physicians and patients to make clinical decisions, and others will relegate much decision making to external agencies. Resolution of the rationing debate awaits the precise configuration of our developing health care system, as determined by the ongoing deliberations in Congress and the pending decision of the US Supreme Court on the constitutionality of the Affordable Care act. ${ }^{6}$

\section{References}

1. Mayer JE. Transcatheter aortic valve implantation should be controlled and monitored by the medical profession. J Thorac Cardiovasc Surg. 2012;143:771-3.

2. Wheatley JH. Use of transcatheter valve should not be rationed. J Thorac Cardiovasc Surg. 2012;143:774-5.

3. American Association for Thoracic Surgery. Code of ethics. Available at: http:// www.aats.org/Association/Policies/Code_of_Ethics.html. Accessed November $18,2011$.

4. Society of Thoracic Surgeons. Code of ethics. Available at: http://www.sts.org/ about-sts/policies/code-ethics. Accessed November 18, 2011.

5. Council on Ethical and Judicial Affairs. Principles of medical ethics. Code of medical ethics, 2010-2011 ed. Chicago, IL: American Medical Association; 2010:xvii.

6. Liptak A. Justices to hear health care case as race heats up. The New York Times. November 14, 2011. 